\title{
Letters
}

To the Editor:

Now that was a nice little jeremiad at the start of the last $C R L$. You must mean it when you say that there are too many librarians about (after all, the English were saying as much at least five years ago). Just the same, whittling the number down, while this would cure the population problem, isn't likely to help libraries much in coping with the nonstop demands being placed upon them nowadays for more and better service. Obviously we face an impasse. Your indicating the size and obstinacy of the impasse doesn't do any harm, I suppose, but certainly makes for depressing reading. And your parting shot-that the glutted job-market will bring down our already deflated salaries-well, there's enough dreariness in that to have anyone wringing his hands. But away with handwringing. What we need now is some good, solid tearing of hair and gnashing of teeth. The old sackcloth-and-ashes bit, you know.

\section{Peter Gellatly}

Serials Librarian

University of Washington Libraries Seattle, Washington

To the Editor:

Hopefully, we can follow the course you recommend in a recent editorial (CRL, Sept. 1972) and can reduce the flood of library school graduates. Perhaps, though, we need to be concerned with the general problem of employment in this country, not just in library science. It may be that in the long run only a national approach with legal force will be effective. One does not have to believe in a command economy to envy the East Germans just a bit. David Childs, in his East Germany (New York: Praeger, 1969), quoted a statement dating from 1965 which indicated only students who were interested in fields where a de- mand existed could expect admittance to institutions of higher education (p. 187). The object was to ensure that the numbers of graduates and jobs balanced. Interestingly, library science was mentioned as one of the areas where prospects were bleak.

Benjamin R. Beede

Assistant Law Librarian

School of Law Library-Camden

Rutgers University

Camden, New Jersey

To the Editor:

David Kaser's very fine "Whither Interlibrary Loan?” (CRL, Sept. 1972) will hopefully stimulate the profession to find ways to prevent the collapse of our loosely hinged, mostly cooperative, nationwide interlibrary loan structure.

I hope that the ". . . growing desire to free up rather than restrict the flow of materials of Scholarship ..." will be strong enough to counter managerial inclinations to shut down the interlibrary system based on an increasingly acute awareness of the “. . . full magnitude of the cost of interlibrary lending. ...."

By the way, it's not only the world of scholarship which is potentially affected here. Our entire national information delivery system will be affected to the extent that we fail or succeed in finding ways to maintain and improve the interlibrary lending system.

\section{Frank Van Zanten \\ Director \\ Tucson Public Library \\ Tucson, Arizona}

To the Editor:

As always, on the first reading of an Ellsworth Mason opus, I enjoyed "A Short Happy View of Our Emulation of Faculty." 
Then, as nearly always seems to be the case with Mr. Mason's writings on topics which do not deal with library buildings, I went back to review the article and found it misleading, rhetorical, and, in essence, almost useless to help us in our current dilemma. The dilemma I am referring to, of course, is whether or not to fight to get or keep faculty status and rank, in the present state of the library profession and in the present state of the academic teaching profession.

I believe that Mr. Mason's facts are consistently wrong in this editorial, and his conclusions, therefore, must necessarily be wrong. In the first place, it is absolutely not true that "in any university of quality, this means no promotion above the rank of instructor without a Ph.D. degree." I challenge $\mathrm{Mr}$. Mason to give me examples of even a very few institutions where this is true. Secondly, it cannot be a fact that the present crop of college teachers are "opportunists," who have very low standards of classroom performance and grading, and at the same time be true that we must compete with "high-powered academicians. ..."What Mr. Mason seems to want us to do, as academic librarians, is to meet some kind of undocumented standards which exist only in his mind and govern the typical teaching faculty member. I have been involved with academic libraries over a period of nearly thirty years, and, although my actual experience is mostly at this medium-sized university, I think that I have been around sufficiently to be a fair judge of what has gone on and is going on in both our profession and the academic profession.

I believe that the new Joint Statement is a good one, and, like all such statements, may well be capable of some modification as experience warrants. But it is an extremely good starting point, and should help the academic librarians and the college teachers to get together on at least a modus vivendi basis, for the foreseeable future.

One last point about Mr. Mason's editorial: it seems to me that to say that "the only faculty benefit denied librarians is a longer vacation" is about like saying the only things lacking in the Venus de Milo are two arms. I, for one, find it extremely distressing to have to spend approximately one-sixth of my working life at the same old grind, while my confrères, who are no more capable of handling their particular jobs than I am of handling mine, are gadding about for two months each summer and for periods between semesters, while I must keep my nose to the grindstone. I do not see that it is at all a fair salary trade that librarians be paid as miserably as most of us are in relationship to standards for teaching faculty, as a sort of recompense for not having to follow the "publish-orperish" and the tenure-or-sink syndromes, as he suggests. As a matter of fact, the latter part is not true at Idaho State University, and, I believe, not true in most institutions of higher learning in this country which do give faculty status and rank. Tenure rules do apply to both professional librarians and teaching faculty, generally.

Sometime, Ellsworth, I would like to have you deliver a statement without being so damned oracular and positive about it! Or do I feel that way because I have some of that tendency myself?

\section{Eli M. Oboler University Librarian Idaho State University Pocatello, Idaho}

